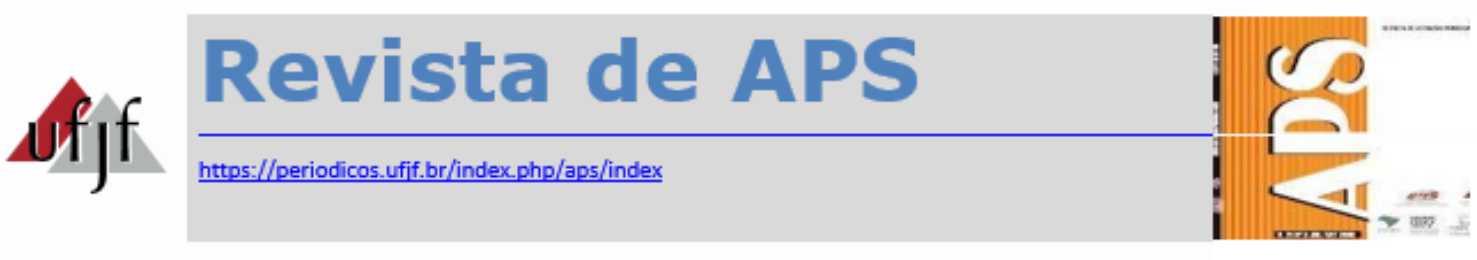

\title{
Análise de prescrições irregulares em uma rede de farmácias do Recife
}

\section{Analysis of irregular prescriptions in a pharmacy of Recife}

Antônio Gustavo de Siqueira Amaral ${ }^{1}$, Francisco Alberto Crasto Lima de Holanda ${ }^{2}$, Tayronni Menezes de Castro $^{3}$, Aline Silva Ferreira ${ }^{4}$, Fabíola Freitas França Galvão de Oliveira ${ }^{5}$, Pedro José Rolim Neto ${ }^{6}$, Rosali Maria Ferreira da Silva ${ }^{7}$

\section{RESUMO}

A prescrição é um "documento" essencial que visa à adesão farmacoterapêutica por meio da tradução completa de informações fundamentais sobre a terapia a ser seguida pelo paciente. Ela deve ser escrita de forma legível, à tinta e ao vernáculo, e conter todas as informações sobre o medicamento. Além disso, características referentes ao prescritor e ao paciente são indispensáveis, pois garantem a confiabilidade e a rastreabilidade da receita perante a Vigilância Sanitária e asseguram o uso racional de medicamentos. Atualmente, o número de prescrições ilegíveis é alto e esse fator contribui para o aparecimento de efeitos adversos, tóxicos e até letais, dependendo do caso. 0 presente estudo teve como objetivos avaliar as prescrições que apresentaram ilegibilidade, bem como sua origem, sua classificação e os principais erros de preenchimento. O projeto foi submetido e aprovado pelo Comitê de Ética. Realizou-se a pesquisa em um dos estabelecimentos da Rede de Farmácias Pague Menos ${ }^{\circledR}$, durante o mês de junho de 2015, sendo analisadas 200 receitas consideradas ilegíveis. Das receitas analisadas, 43 (22\%) não possibilitaram a dispensação do medicamento. Constatouse, também, que a maioria das receitas veio de estabelecimentos públicos (60\%) e que $74 \%$ era de controle especial. Além disso, observou-se a ausência de informações importantes no receituário, como duração do tratamento, posologia e data. Desse modo, essas características comprovam que a ilegibilidade é uma prática recorrente, que impossibilita uma dispensação segura de medicamentos

\footnotetext{
${ }^{1}$ Farmacêutico, Universidade Federal de Pernambuco (UFPE).

${ }^{2}$ Farmacêutico, Universidade Federal de Pernambuco (UFPE).

${ }^{3}$ Coordenador dos Farmacêuticos, Universidade Federal de Pernambuco (UFPE).

${ }^{4}$ Farmacêutica, Centro Universitário Maurício de Nassau (UNINASSAU).

${ }^{5}$ Farmacêutica/Graduada, Centro Universitário Estácio do Recife.

${ }^{6}$ Professor, Universidade Federal de Pernambuco (UFPE)

${ }^{7}$ Professora, Universidade Federal de Pernambuco (UFPE).
} 
nos estabelecimentos de saúde e, consequentemente, comprova a grande importância da padronização no preenchimento de receitas para que haja uma eficácia no tratamento.

PALAVRAS-CHAVE: Erros de medicação; Legibilidade; Prescrição médica.

\begin{abstract}
The prescription is an essential "document" that aims to pharmacotherapeutic adherence through the complete translation of key information about the therapy to be followed by the patient. As such, it must be written legibly in ink and vernacular, and contain all the medicine information. In addition, features of the prescriber and the patient are indispensable, as they ensure the reliability and traceability of the recipe before the Health Surveillance, and ensure the rational use of medicines. Currently, the number of illegible prescriptions is high and this factor contributes to the appearance of side effects, toxic and even lethal damage, depending on the case. This study aimed to evaluate the prescriptions that presented illegibility, as well as their origin, their classification and their main filling errors. The project was approved by the Ethics Committee. The survey was conducted in one of the establishments of pharmacies PagueMenos ${ }^{\circledR}$ Network, during the month of June 2015 , which analyzed 200 recipes considered unreadable. Of the recipes analyzed, 43 (22\%) did not allow the dispensing of the drug. It was also found that most recipes were coming from public institutions (60\%) and that $74 \%$ were prescriptions of Special Control. Furthermore, there is the absence of significant information on prescriptions, as duration of treatment, dosage, date. Thus, these features prove that illegibility is a recurring practice that prevents a safe drugs dispensing in health facilities and proves the importance of standardization of recipes allowing treatment effectiveness.
\end{abstract}

KEYWORDS: Medication errors; Illegibility; Prescription drugs.

\title{
INTRODUÇÃO
}

Segundo a Organização Mundial da Saúde (OMS), a prescrição apropriada é uma das etapas mais significativas que compreendem o uso racional de medicamentos. Ela caracteriza, de forma documentada, o tratamento a que o paciente foi submetido, sendo o principal elo de comunicação entre prescritores, farmacêuticos e pacientes. ${ }^{1,2}$

Em detrimento às diversas classes farmacológicas e seu grau de dependência sob os usuários, as prescrições categorizaram-se em notificações do tipo A, B e C, para que esses medicamentos possam ser monitorados e controlados pelas agências de saúde. ${ }^{3}$

Segundo a Portaria no 344, de 12 de maio de 1998, a Notificação de Receita é um "Documento padronizado destinado à notificação da prescrição de medicamentos". Ela estabelece os tipos de receitas e, consequentemente, as substâncias que devem ser prescritas. ${ }^{4}$ 
As receitas do tipo $A$, de cor amarela, são utilizadas para a prescrição de medicamentos entorpecentes, presentes nas listas "A1" e A2", e têm como exemplos dessa classificação a morfina e a codeína, respectivamente. Tais receituários apresentam uma validade de 30 dias e são fornecidos pela Vigilância Sanitária..$^{5-7}$

As receitas do tipo $B$, de cor azul, são utilizadas para a dispensação de medicamentos psicotrópicos presentes nas listas "A3" e "B1"; e os anorexígenos, na lista "B2". Como exemplos dessas listas, temos o diazepam e a sibutramina. O talonário é impresso pelo próprio médico, a partir da numeração fornecida pela Vigilância Sanitária, possuindo uma validade de 30 dias. ${ }^{5-7}$

As receitas do tipo C, de cor branca, servem para a prescrição de substâncias de controle especial. Estas apresentam uma validade de 30 dias (com exceção dos antimicrobianos que apresentam uma validade de 10 dias) e são impressas pelo médico. ${ }^{5,6}$

Sabe-se que, para a dispensação segura dos medicamentos, torna-se indispensável que as receitas estejam preenchidas corretamente e com clareza. Dessa maneira, qualquer falha no preenchimento poderá acarretar a não dispensação do medicamento ou possíveis erros e consequentes falhas no tratamento.

Mesmo com diferentes tipos de receituários, é importante salientar que eles devem seguir um padrão de preenchimento, contendo todas as informações necessárias para uma dispensação segura e de qualidade. Os dados essenciais que compreendem o preenchimento adequado das prescrições são compostos por data; assinatura; cabeçalho, com o nome e o endereço do profissional ou da instituição onde trabalha, o registro profissional e o número de cadastro de pessoa física ou jurídica; superinscrição, com o nome e o endereço do paciente; inscrição, contendo o nome do fármaco, sua concentração e sua forma farmacêutica; subscrição, que determina a quantidade total do medicamento a ser fornecida; e descrição, composta pelas orientações adicionais do profissional para o paciente. ${ }^{6}$

Os principais erros de medicação ocorrem pela deficiência da legibilidade dos receituários. ${ }^{8}$ Inconformidades nas prescrições de medicamentos podem levar ao uso inadequado deles, gerando a prática abusiva de tais substâncias ou sua utilização reduzida. Dessa forma, o aparecimento de reações adversas e tóxicas no organismo e a ineficácia terapêutica podem ser fatores desencadeados por esse processo. ${ }^{9}$ 
No Brasil, existem regulamentações que regem a padronização das prescrições por meio de Portarias, Leis e Resoluções. A Lei Federal no 5.991/73 traz em seu artigo no 11 exigências relacionadas à legibilidade e ao preenchimento adequado das receitas. Há, também, aspectos a serem seguidos pela Lei Federal no 9.787/99; pela Resolução no 357/01 do Conselho Federal de Farmácia (CFF); pelo Código de Ética Médica (CEM); e pelo Código de Ética da Profissão Farmacêutica (CEPF). ${ }^{3,10-14}$

Este trabalho teve como objetivo analisar prescrições ilegíveis e a quantificação da ausência de informações importantes nesses receituários, como forma de orientação e sensibilização dos profissionais de saúde, quanto à importância da qualidade da prescrição, seguindo a padronização vigente nas normas brasileiras. Assim, possibilitamse a dispensação e a administração segura de medicamentos, promovendo seu uso racional e proporcionando mais eficácia e adesão farmacoterapêutica ao paciente.

\section{METODOLOGIA}

\section{Material}

Foram utilizadas 200 receitas ilegíveis e formulários de avaliação que continham campos de preenchimento para a caracterização dessas receitas com relação aos principais erros de preenchimento (posologia, dosagem, data, duração do tratamento e identificação de emitente), os tipos de receituários de controle especial (listas C1 e C5, de notificação " $A$ " e de notificação "B") e sua origem (rede de saúde pública ou privada).

\section{Método}

A pesquisa foi executada em um dos estabelecimentos da rede de drogarias Pague Menos ${ }^{\oplus}$, localizada na Rua Dr. Bandeira Filho, no 160, no bairro das Graças, município de Recife, em Pernambuco, com a avaliação de 200 prescrições que continham irregularidades, retidas na farmácia durante o mês de junho de 2015. Dessa forma, para a identificação e a organização dos dados, utilizou-se o formulário de avaliação, seguindo as normas prescritivas descritas na Portaria no 344, de 12 de maio de 1998, as Leis Federais no 5.991/1973 e no 9.787/1999, a Resolução no 357/2001 CFF, 
o CEM, o Código de Ética do Médico-veterinário (CEMV) e o Código de Ética Odontológica (CEO). ${ }^{4,10-13,15,16}$

Durante todo o procedimento, o pesquisador esteve acompanhado do profissional farmacêutico para eventuais dúvidas. Após a compilação dos dados obtidos e da análise quantitativa, utilizam-se os programas Microsoft Office Word ${ }^{\oplus}$ e Excel ${ }^{ø}$ para demonstrar o percentual de cada erro de preenchimento encontrado nas receitas classificadas como ilegíveis e o tipo de receita que mais apresentou ilegibilidade. Assim, pôde ser definido se a maior percentagem de ilegibilidade teve origem em estabelecimentos de saúde públicos ou privados. Quanto aos aspectos éticos, a pesquisa foi cadastrada mediante o no CAAE 38705114.9.0000.5208 e submetida e aprovada no Comitê de Ética em Pesquisa Envolvendo Seres Humanos da UFPE.

\section{RESULTADOS}

Em junho de 2015, analisaram-se 200 receitas médicas que apresentaram um maior grau de dificuldade de leitura e compreensão, constatando-se sua ilegibilidade. Essa falta de entendimento gerou dúvidas quanto ao que foi prescrito, impossibilitando que 43 receituários (22\%) tivessem sua medicação dispensada aos pacientes pela ausência de legibilidade da receita.

Ao analisar a origem das prescrições ilegíveis, constatou-se que 120 (60\%) provinham de estabelecimentos públicos e 80 (40\%) vieram do setor privado de saúde. Foram avaliadas as substâncias presentes apenas nas listas "C1" e "C5". Das receitas ilegíveis, contatou-se que a maioria delas era de controle especial (74\%). Em segundo lugar, ficaram as receitas de notificação "B" (25\%) e, por último, as de notificação " $A$ " (1\%).

Constatou-se que, das 200 receitas ilegíveis, 120 (60\%) apresentavam algum tipo de erro de preenchimento - algumas delas com até mais de uma falha encontrada. Os principais erros constatados são demonstrados, na página seguinte, na Figura 1. 
Figura 1 - Principais erros de preenchimento encontrados nas receitas ilegíveis na rede de farmácias Pague Menos ${ }^{\oplus}$

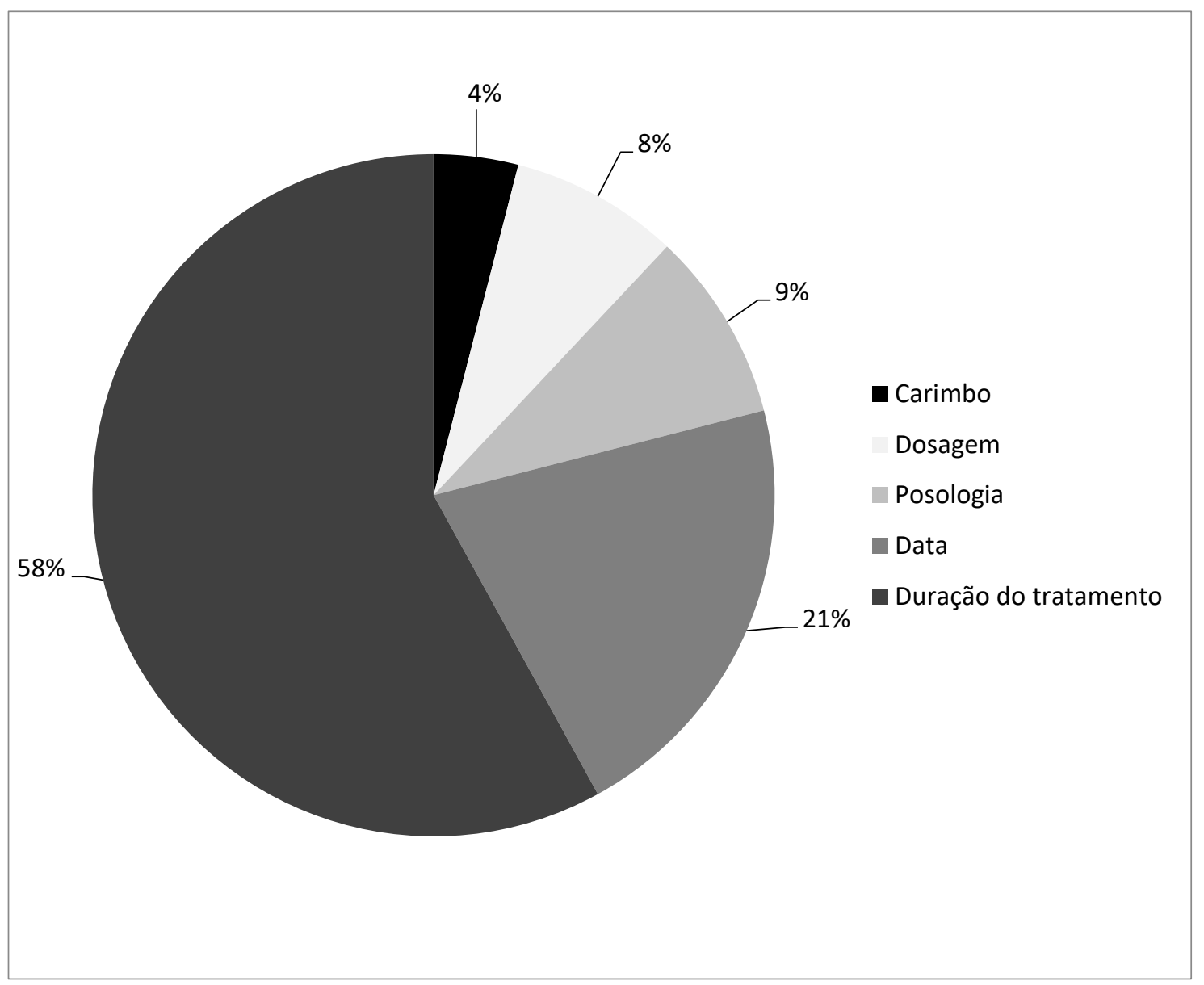

Fonte: Elaborado pelos autores

Do total de receitas ilegíveis, 43 (29\%) não puderam ser dispensadas ao paciente, por não apresentarem a dosagem específica do medicamento ou a data da prescrição. Entre as receitas analisadas, a duração do tratamento foi o quesito que menos esteve presente, caracterizando o maior índice de erro de preenchimento e estando ausente em 93 receituários (58\%). O comprometimento desse quesito pode levar a falhas na adesão do tratamento no que diz respeito à farmacoterapia adequada.

Dessas 200 (17\%) receitas ilegíveis, 9 (8\%) delas não apresentaram a dosagem correta do medicamento prescrito. Tal erro de preenchimento pode levar ao retardamento ou à interrupção de um tratamento. Isso porque não pode haver a dispensação do fármaco. Das receitas analisadas, 4\% delas apresentavam ilegibilidade no carimbo, infringindo o artigo no 39 do CEM. 


\section{DISCUSSÃO}

A prescrição é um instrumento legal de comunicação entre os profissionais de saúde e o paciente. De acordo com o artigo no 11 do CEM, "é vedado ao médico receitar ou atestar de forma secreta ou ilegível" ${ }^{13}$ Mesmo assim, o ato de prescrever de modo incompreensível é um dos erros mais habituais e observados diariamente nos estabelecimentos de saúde. ${ }^{17}$

Alguns estudos, como o nosso, demonstram o descumprimento das exigências legais da prescrição de medicamentos no Brasil, vigentes na Portaria no 344/98.4,18,19 Essa violação pode desencadear diversos riscos à saúde da população, no que diz respeito ao aumento das reações adversas medicamentosas, provocadas, muitas vezes, por negligências profissionais, falta de atenção ou péssimas condições de trabalho. ${ }^{20}$

Como a prescrição deve ser entendida, e não interpretada, para a aplicação dos critérios de legibilidade e ilegibilidade, as palavras dos receituários foram examinadas e avaliadas separadamente, com o intuito de evitar possíveis interpretações. A legibilidade caracteriza-se pelo entendimento fácil do que foi escrito, sem a presença de dúvidas ou gasto de tempo excessivo para se entender. A ilegibilidade nada mais é do que a falta de compreensão do que está escrito. ${ }^{21,22}$

As prescrições advindas da rede pública apresentaram uma quantidade discrepante de prescrições ilegíveis quando comparadas com as da rede privada. Isso se torna uma característica importante que deve ser levada em consideração, pois a precariedade vigente nos diversos setores da saúde pública, desde o atendimento ineficiente até as condições ambulatoriais decadentes, pode ser um fator responsável por essa ocorrência.

Entre esses fatores, a grande quantidade de pacientes a ser atendida nas filas de espera geralmente demanda um menor tempo de atendimento individualizado do paciente. Além disso, as precárias condições ambulatoriais e a falta de materiais de apoio impossibilitam que as receitas venham a ser digitalizadas. Nisso, as jornadas de trabalho excedentes exercidas pelos médicos também podem influenciar em maior ilegibilidade, uma vez que esses profissionais podem não estar em condições fisiológicas adequadas.

Com o efeito da ascensão tecnológica, o aumento no número de medicamentos 
em suas diferentes classificações, sugeridas pela OMS, exigiu que a prescrição fosse feita em receituários padrões ou em notificações específicas com o intuito de garantir a segurança e o controle rigoroso na dispensação. ${ }^{5,23}$ Observou-se que, das 200, 9 (8\%) delas não apresentaram a dosagem correta do medicamento prescrito. A dosagem específica ou a data da prescrição são dois fatores indispensáveis em uma prescrição, pois garantem a farmacoterapia adequada ao referente quadro clínico e o controle da validade das receitas perante a vigilância sanitária, bem como a segurança do paciente com relação ao uso de medicamentos após o prazo para início do tratamento. ${ }^{7}$

A duração do tratamento é um fator relacionado ao tempo de terapia a que o indivíduo será submetido. Dessa forma, determina-se o prazo para o uso correto do medicamento, evitando possíveis interrupções ou retardamento terapêutico. A possível interrupção do tratamento, muitas vezes, dá-se por conta dos próprios pacientes, visto que, ao apresentarem uma relativa melhora clínica, acreditam que o uso do fármaco não seja mais necessário. Tal fato deve ser levado em consideração, já que, com frequência, a doença não foi sanada completamente e, depois, pode ocorrer o reaparecimento dos sintomas.

A exemplo disso, a suspensão de tratamentos com antibióticos, antes do tempo recomendado pelo médico, pode levar a uma resistência bacteriana ao medicamento. Isso acontece quando o tempo de ação do fármaco não é eficaz na eliminação das cepas mais resistentes, as quais acabam se multiplicando e levando a uma infecção bem mais resistente. Consequentemente, torna-se ineficaz o uso do mesmo medicamento, sendo necessária a utilização de outro mais forte. ${ }^{24}$

O retardamento terapêutico pelo uso exacerbado do medicamento, sem a necessidade terapêutica, caracteriza inúmeras consequências indesejáveis ao indivíduo, a curto, médio ou longo prazos. Com relação a esses efeitos, estão "o exponencial aumento de efeitos colaterais, reações alérgicas, dependência, envenenamento e complicações hepáticas e hematológicas" ${ }^{25}$

Segundo a alínea "C" do artigo 35 da Lei no 5.991/1973, "somente será aviada a receita que contiver a data de prescrição". Este parâmetro certifica o dia em que a receita foi prescrita, garantindo sua validade. Cada receita apresenta uma validade específica. Os receituários de controle especial e os de notificação " $A$ " e "B" têm uma validade de 30 (trinta) dias, a contar da data de emissão. ${ }^{4}$ Caso não haja a datação da 
receita, o farmacêutico poderá entrar em contato com o médico para tirar quaisquer dúvidas sobre o dia da consulta. Caso essa comunicação não possa ser estabelecida, ela não poderá ser expedida.

Isso acarretará a impossibilidade de início do tratamento. Consequentemente, poderá desencadear sérios danos na saúde do paciente, porque ele não fazia o devido uso da medicação no tempo previsto. Nos casos em que a validade da receita esteja expirada, o paciente deverá submeter-se a uma nova consulta. Isso impossibilitará que ele venha a usar o fármaco de uma forma indiscriminada, por não se saber o quadro clínico em que se encontra, garantindo-se a segurança do paciente contra o surgimento de possíveis efeitos adversos.

Um esquema posológico racional tem como objetivo garantir o efeito terapêutico desejado, pela manutenção constante da janela terapêutica. Ele compreende a concentração plasmática mínima do fármaco, necessária para fazer o efeito desejado no organismo, indicando a quantidade a ser tomada, o intervalo de tempo de administração entre as doses e a via de administração.

A ausência da posologia ou sua indicação incorreta podem levar ao uso indevido do medicamento e, consequentemente, gerar sérios problemas de saúde para o paciente. Entre as principais consequências, estão a falha na adesão do tratamento e o aparecimento de reações adversas e tóxicas, podendo levar à morte.

Os carimbos devem apresentar com clareza os dados do profissional prescritor, já que o número de inscrição do CRM e seu nome garantem a confiabilidade da origem da receita, possibilitando um elo de comunicação entre os diversos profissionais de saúde. ${ }^{13}$

Não há exigência legal da presença do carimbo do médico, do veterinário e do dentista em receitas. Entretanto, a assinatura com identificação clara do profissional e seu respectivo CRM, CRMV e CRO são imprescindíveis na receita. Dessa forma, o carimbo tem apenas como finalidade a garantia da originalidade e a consequente confiabilidade da prescrição.

Com a análise das receitas na rede de farmácias Pague Menos, na cidade de Recife, durante o mês junho de 2015, constatou-se que a falta de legibilidade das prescrições é um problema de saúde bastante comum ainda nos dias atuais. Tal fator pode impossibilitar a dispensação do medicamento para o paciente, reduzindo a 
efetividade do tratamento e aumentando o risco de internação hospitalar. Além disso, há perda de tempo, perda de investimentos com relação a gastos adicionais com consultas e exames e, possivelmente, complicações ao quadro clínico do indivíduo. ${ }^{26}$

Destaca-se a importância da análise de prescrições dentro dos serviços de saúde como modo de avaliar se o serviço está levando aos pacientes prescrições conforme o que é preconizado na legislação e também de corrigir erros que sejam encontrados, visando a garantir uma atenção básica de qualidade e um tratamento mais seguro. Infelizmente, nem todas as universidades abrangem, nos cursos médicos, odontológicos e veterinários, as orientações e informações necessárias a respeito do preenchimento correto e legível das prescrições. Essa deficiência no ensino contribui de forma significativa para o aumento no índice de erros e na falta de legibilidade, constatados na prática profissional.

O não cumprimento dessas regras caracteriza um ato infracional da profissão, sendo passível a penalidades previstas pelos Códigos de Ética Médica, Odontológica e do Médico-veterinário. Além disso, as leis de bases e diretrizes da saúde pública do país garantem que o não cumprimento desses fatores fere os direitos à cidadania dos brasileiros. ${ }^{13,15,16}$

Dessa forma, o uso de prescrições legíveis e sem rasuras é imprescindível para minimizar as chances de erros de medicação e obter resultados satisfatórios para o paciente. Nesse sentido, as prescrições digitalizadas e eletrônicas são as formas mais seguras de evitar a ilegibilidade, mas é uma realidade ainda pouco exercida nas unidades de saúde, devido, principalmente, aos custos elevados e à falta de recursos destinados a essa prática. Caso os prescritores tenham essa deficiência, devem procurar meios para garantir que as informações sejam passadas adequadamente, seja por pela melhora da caligrafia seja pelo investimento de instrumentos eletrônicos para a utilização de prescrições digitalizadas.

\section{CONCLUSÃO}

Os resultados mostraram que a maior parte das prescrições médicas analisadas no estudo encontrava algum tipo de irregularidade, desde a falta de legibilidade que impossibilitou a dispensação de medicamentos até erros de preenchimento, 
ocasionando prejuízo aos pacientes.

A partir disso, a atenção básica à saúde caracteriza-se por um conjunto de ações de promoção, proteção e recuperação da saúde, no âmbito individual e coletivo, priorizando a integralidade do cuidado. Nesse contexto, a prescrição médica assume um papel fundamental para o sucesso da farmacoterapia e da recuperação da saúde.

Nesse momento, levanta-se a necessidade de uma conscientização dos profissionais prescritores em relação à importância do cumprimento da legislação brasileira sobre a prescrição de medicamentos. Os farmacêuticos por sua vez, devem exigir a prática correta da prescrição, pois tornam-se responsáveis por quaisquer consequências significativas à saúde do paciente se o medicamento for dispensado incorretamente. Dessa forma, caso haja a ilegibilidade, o farmacêutico não deverá dispensar a medicação ou deverá entrar em contato com o médico para esclarecer o que não foi compreendido, garantindo a segurança e a saúde do paciente. Por fim, é indispensável também que os próprios pacientes exijam, no ato da consulta, que as receitas estejam legíveis e tirem quaisquer dúvidas existentes na prescrição, pois $a$ "transparência da informação, a compreensão da receita médica e o conhecimento da prescrição proporcionam a adesão ao tratamento" ${ }^{6}$

\section{REFERÊNCIAS}

1. Haayer F. Rational prescribing and sources of information. Soc Sci Med. 1982; 16(23):2017-2023.

2. Valladao MLF, Lisboa SM, Fernandes C. Receitas médicas e dispensação farmacêutica: uma questão de saúde. Rev Med Minas Gerais. 2004; 14(1): 17-21.

3. Cabral MN. Erros de prescrição em hospitais brasileiros: uma revisão [Trabalho de Conclusão de Curso]. João Pessoa: Universidade Federal da Paraíba; 2014.

4. Brasil. Ministério da Saúde. Portaria no 344 de 12 de maio de 1998. Aprova o Regulamento Técnico sobre substâncias e medicamentos sujeitos a controle especial. [citado 2015 ago 01] Disponível em: http://www.anvisa.gov.br/scriptsweb/anvisalegis/VisualizaDocumento.asp?ID=93 $9 \&$ Versao $=2$.

5. Barros E, Barros HMT. Medicamentos na prática clínica. Porto Alegre: Artmed; 2010. p. 33-44.

6. Madruga CMD, Souza ESM. Manual de orientações básicas para prescrição médica. Arquivos do CRM-PB. 2012; 29(114): 1-20. 
7. Brasil. Agência Nacional de Vigilância Sanitária. Resolução no 44, de 17 de agosto de 2009. Dispõe sobre Boas Práticas Farmacêuticas para o controle sanitário do funcionamento, da dispensação e da comercialização de produtos e da prestação de serviços farmacêuticos em farmácias e drogarias e dá outras providências. Diário Oficial da União, Poder executivo, Brasília, DF, 17 de agosto de 2009. [citado 2015 ago 01] Disponível em: http://cfo.org.br/wpcontent/uploads/2010/02/180809_rdc_44.pdf.

8. National Coordinating Council for Medication Error Reporting and Prevention. Taxonomy of Medication Errors. [citado 2015 set 01]. Disponível em: http://www.nccmerp.org/sites/default/files/taxonomy2001-07-31.pdf.

9. Azevedo LS, Pereira LJ, Zangerônimo MG, Sousa RV, Murgas LDS, Marques LS et al. Avaliação da adequação legal de receitas e notificações de receita de medicamentos sujeitos a controle especial dos setores públicos e privados. Rev de Ciênc Farm Básica Apl. 2012 ; 32(3): 411-417.

10. Conselho Federal de Farmácia. Resolução no 357 de 20 de abril de 2001. Aprova o regulamento técnico das Boas Práticas de Farmácia. Brasília: Conselho Federal de Farmácia, 2001. [citado 2015ago 12] Disponível em: http://www.cff.org.br/userfiles/file/resolucoes/357.pdf.

11. Brasil. Presidência da República. Lei no 5.991 de 17 de dezembro de 1973. Dispõe sobre o controle sanitário do comércio de drogas, medicamentos, insumos farmacêuticos e correlatos, e dá outras providências. [2015 ago 01]. Disponível em: http://www.planalto.gov.br/ccivil_03/leis/L5991.htm.

12. Brasil. Presidência da República. Lei no 9.789 de 10 de fevereiro de 1999. Altera a Lei $n^{\circ} 6.360$, de 23 de setembro de 1976, que dispõe sobre a vigilância sanitária, estabelece o medicamento genérico, dispõe sobre a utilização de nomes genéricos em produtos farmacêuticos e dá outras providências. [citado 2015 ago 01]. Disponível em: http://www.planalto.gov.br/ccivil_03/leis/L9787.htm.

13. Conselho Federal de Medicina. Resolução no 1.931 de 24 de setembro de 2009. Dispõe sobre o Código de Ética Médica. [citado 2015 jul 12]. Disponível em: http://www.cremego.cfm.org.br/index.php?option=com_content\&view=article\&i $d=21000$.

14. Conselho Federal de Farmácia. Resolução no 596 de fevereiro de 2014. Dispõe sobre o Código de Ética Farmacêutica, o Código de Processo Ético e estabelece as infrações e as regras de aplicação das sanções disciplinares, 2014. [citado 2015 ago 12]. Disponível em: http://www.cff.org.br/userfiles/file/resolucoes/596.pdf.

15. Conselho Federal de Medicina Veterinária. Resolução no 722 de 16 de agosto de 2002. Aprova o Código de Ética do Médico Veterinário. [citado 2015 set 02]. Disponível em: http://portal.cfmv.gov.br/portal/lei/index/id/234.

16. Conselho Federal de Odontologia. Resolução no 118 de 11 de maio de 2012. Aprova o Código de Ética Odontológica. [2015 set 02]. Disponível em: http://cfo.org.br/legislacao/codigos/. 
17. Martins R. Análise gráfica de receitas médicas. Uma contribuição do design da informação para a detecção e prevenção de erros latentes. [Dissertação]. Curitiba: Universidade Federal do Paraná; 2009.

18. Ferrari CKB, Brito LF, Oliveira CC, Moraes EV, Toledo OR, David FL. Falhas na prescrição e dispensação de medicamentos psicotrópicos: um problema de Saúde Pública. Rev Ciên Farm Básica e Apli. 2013; 34(1): 109-116.

19. Silvério MS, Leite ICG. Qualidade das prescrições em município de Minas Gerais: uma abordagem farmacoepidemiológica. Rev Assoc Med Bras. 2010; 56(6):675680.

20. Valadão AF, Moreira ALP, Andrade LC, Pires CA, Firmino KF, Brum CA. Prescrição médica: um foco nos erros de prescrição. Rev Bras Farm. 2009; 90(4): 340-43.

21. Rosa MB. Erros de medicação em um hospital referência de Minas Gerais [Tese]. Belo Horizonte: Universidade Federal de Minas Gerais, 2002.

22. Aguiar G, Silva Júnior LA, Ferreira MAM. Ilegibilidade e ausência de informação nas prescrições médicas: fatores de risco relacionados a erros de medicação. Rev Bras Prom Saúde. 2012; 19(2): 84-91.

23. Néri EDR, Gadêlha PGC, Maia SG, Pereira AGS, Almeida PC, Rodrigues CRM, et al. Erros de prescrição de medicamentos em um hospital brasileiro. Ver Assoc Med Bras. 2011; 57(3): 306-314.

24. MD Saúde. Antibióticos: tipos, resistência e indicações. [2015 out 28] Disponível em: http://www.mdsaude.com/2011/02/antibioticos.html.

25. Santos J. Consumo excessivo de medicamentos, um problema de saúde pública. Rev RET-SUS. 2012; 7(55): 6-9.

26. Anacleto TA, Rosa MB, Neiva HM, Martins MAP. Erros de medicação. PharmBras. $2010 ; 74: 1-24$.

Submissão: outubro de 2017.

Aprovação: abril de 2018. 